\title{
Agroecologia e Gênero: Perspectivas Para a Emancipação das Mulheres e a Agricultura Familiar
}

\author{
Agroecología y Género: perspectivas para el empoderamiento de las \\ mujeres y la agricultura familiar
}

\section{Agroecology and Gender: Perspectives on Women Emancipation and Family Farming}

Esp. Daiana Paula Varotto 1

\begin{abstract}
Resumo
O presente estudo objetiva analisar a relação entre a participação da mulher na agricultura familiar e suas perspectivas de emancipação através de práticas sócio-econômicas na atividade agroecológica. Utiliza-se nesse trabalho como delimitação espacial o Alto Uruguai/RS e delimitação temporal os anos de 2005-2015 em justificativa as atividades desenvolvidas junto a agricultura familiar das depoentes. Enquanto procedimento metodológico utiliza-se o bibliográfico-investigativo e o uso de metodologia de História Oral temática. Nesse estudo foram entrevistadas dez mulheres residentes em quatro municípios da região Norte do Rio Grande do Sul.
\end{abstract}

Palavras-chave: Agricultura familiar; agroecologia; emancipação; gênero.

\section{Resumen}

El presente estudio objetiva analizar la relación entre la participación de la mujer en la agricultura familiar y sus perspectivas de emancipación por medio de prácticas socioeconómicas en la actividad agroecológica. Se utiliza nese trabajo como delimitación espacial el Alto Uruguai/RS y delimitación temporal los años de 2005-2015 en justificación las actividades desarrolladas junto a la agricultura familiar de las declarantes. Mientras procedimiento metodológica se utiliza el bibliográfico investigativo y el uso de metodologia de História Oral temática. Nese estudio fueron entrevistadas diez mujeres residentes en cuatro municipios de la región Norte de Rio Grande do Sul.

Palavras claves: Agricultura familiar; agroecología; emancipación; género.

Abstract

This study mains to analyse the relationship between the participation of the woman in the family farming and her prospects of emancipation through socio-economic practices in agroecological activity. In this work, it is used as a space delimitation the region Alto Uruguai/RS and as a temporal delimitation the years from 2005 and to 2015 on justification to the activities developed along with family farming of the deponents. As methodological procedure, it is used the bibliographic investigative and the use of the thematic Oral History methodology. In this study were interviewed ten women that live in four towns in the North of Rio Grande do Sul.

Keywords: Family farming; agroecology; emancipaton; gender.

\section{INTRODUÇÃO}

A mulher historicamente foi considerada como incapaz de se auto gerir e esteve

\footnotetext{
${ }^{1}$ Especialista em Agricultura Familiar e Desenvolvimento Sustentável; Universidade Estadual do Rio Grande do Sul - UERGS; Erechim, Rio Grande do Sul, Brasil, daianavarotto@gmail.com.
} 
subordinada ao ideário patriarcal, bem como ao ambiente sócio-cultural, econômico e político, deixando-a em grande parte do tempo restrita aos espaços privados.

Ainda hoje este processo de emancipação, de escolha sobre sua vida pública e profissional, direito ao seu corpo, sofre imposições da sociedade. Em se tratando de mulher da agricultura familiar percebe-se um desafio ainda maior, seja em razão pelo espaço a qual estão inseridas, às vezes pela distância geográfica, outras pela baixa escolaridade ${ }^{2}$ ou pela própria construção social histórica.

O presente trabalho tem por objetivo geral analisar a contribuição das práticas em agroecologia para a emancipação das mulheres da agricultura familiar na região do Corede ${ }^{3}$ Norte do Rio Grande do Sul e como objetivos secundários contextualizar o histórico da participação das mulheres trabalhadoras rurais na luta por seus direitos, analisar a influência da agroecologia e a produção de produtos orgânicos como forma de emancipação das mulheres na agricultura familiar desta região e verificar se de alguma forma as organizações, como sindicatos e cooperativas, promovem o empoderamento ${ }^{4}$ feminino.

A agricultura foi um elemento chave para o desenvolvimento regional, bem como para a construção da mentalidade local. Desde o início da colonização se buscou fomentar a

2 Sabe-se que até meados do século XX a educação rural (na realidade, a educação da maioria da população brasileira, até então predominantemente rural) esteve fora do quadro de preocupações do Estado. Isto significa que o interesse pela educação rural surge, no Brasil, no momento em que o analfabetismo começa a incomodar a cidade, para onde o desenvolvimento industrial e a expansão do comércio e dos serviços em geral passam a carrear levas crescentes de migrantes rurais, em grande parte analfabetas ou semi-alfabetizadas. Quase a dizer-se que o interesse pela educação rural é produto dos movimentos de industrialização e urbanização do país; ou então, que passa a ser importante alfabetizar e escolarizar o campo, porque a cidade o exige. Registra-se também a organização dos movimentos sociais quando reivindicavam a melhoria da qualidade no campo e dentre elas a ampliação de escolas na área rural.

3 COREDE é um fórum que discute e decide sobre políticas públicas e ações que buscam o desenvolvimento regional. O Corede Norte compreende a região do Estado do Rio Grande do Sul formada pelos municípios de Aratiba, Áurea, Barão de Cotegipe, Barra do Rio Azul, Benjamim Constant do Sul, Campinas do Sul, Carlos Gomes, Centenário, Charrua, Cruzaltense, Entre Rios do Sul, Erebango, Erechim, Erval Grande, Estação, Faxinalzinho, Floriano Peixoto, Gaurama, Getúlio Vargas, Ipiranga do Sul, Itatiba do Sul, Jacutinga, Marcelino Ramos, Mariano Moro, Paulo Bento, Ponte Preta, Quatro Irmãos, São Valentim, Sertão, Severiano de Almeida, Três Arroios e Viadutos. De acordo com a Fundação de Economia e Estatística do Rio Grande do Sul (2015) possui uma área de $6.364,2 \mathrm{~km}^{2}$ e população de 227.833 habitantes.

4 Em 1977, o psicólogo norte-americano Julian Rappaport cunhou o termo "empowerment" a partir da palavra "power" ("poder") para defender que era preciso dar ferramentas a certos grupos oprimidos para que eles tivessem condições e autonomia de se desenvolver. O educador brasileiro Paulo Freire criou sua versão do termo para debater a proposta de Rappaport: para ele, eram os próprios grupos desfavorecidos que deveriam empoderar-se a si próprios, uma noção que se tornou popular entre educadores e sociólogos. A palavra foi adotada por movimentos sociais e hoje é largamente utilizada, inclusive por entidades como a Organização das Nações Unidas. Conceito fundamental para explicar as principais faces de movimentos sociais que defendem mais participação social e oportunidades para minorias. 
pequena propriedade e as policulturas para evitar o esgotamento dos solos e para facilitar a subsistência dos imigrantes e dos migrantes. Uma tendência que se manteve firme nas primeiras décadas do século XX, até a implementação da Revolução Verde.

A Revolução Verde foi implantada no Brasil nas décadas de 1960 e 1970, durante o Regime Militar, trouxe para o campo um pacote de aparatos tecnológicos que influenciaram diretamente nas relações dos agricultores com sua forma de produção, suas relações sociais e os principais métodos de produção que tinha contigo são a inserção de agrotóxicos e de fertilizantes sintéticos nas lavouras com a promessa de menos trabalho e de que estas novas ferramentas fariam o papel de acabar com a fome do mundo.

Entretanto, essa nova forma de produzir, especialmente pelo exacerbado incentivo ao uso de agrotóxicos e suas consequências ambientais e para a saúde de fez com que surgisse um contraponto a essa forma de produção, hoje considerada como tradicional, a produção de alimentos orgânicos, ou seja, livres de contaminação por venenos e com técnicas que valorizam o que a natureza tem por si só.

A metodologia usada para elaboração deste trabalho foi a partir de uma abordagem quanti qualitativa, onde é feita uma revisão bibliográfica acerca do que já foi produzido sobre o tema, e por meio do uso de metodologia de história oral temática, foram realizadas entrevistas com roteiro semi-estruturado, visando colher depoimentos que ajudem a elucidar os objetivos propostos. Para dar conta dos mesmos, o trabalho está dividido em três secções, sendo a primeira sobre mulheres e gênero, a segunda contextualizando historicamente a região geográfica de análise, a terceira parte a análise dos dados coletados na pesquisa de campo e para finalizar as conclusões.

\section{Gênero e Mulheres}

Historicamente a mulher foi deixada a sombra da história. Assim sendo, foi mantida distante dos processos de protagonismo sócio-históricos. As grandes revoluções, feitos e governanças, bem como o espaço público não eram lugar dela, já que o mundo foi moldado pelo viés essencialmente masculino o que lhe relegou o menosprezo, a discriminação e incapazes de assumir trabalhos e posições em diversos espaços na sociedade.

A conquista destes espaços considerados do 'homem' foram seguidas de árduas lutas, muitas delas pagas até com vidas. A Constituição Federal de 1988 aponta que homens e mulheres são iguais em direitos e deveres, porém são inúmeras as diferenças vivenciadas diariamente pelas mulheres. 
Quando tratamos da mulher e as relações de gênero ultrapassam a questão entre o biológico de ser masculino ou feminino. De acordo com Wenczenovicz e Rangel (2016):

As discussões teóricas sobre gênero podem ser divididas entre as relacionadas às características sexuais biológicas, supostamente fixas ou geneticamente determinadas na diferença entre homem e mulher, ou culturalmente determinadas, de onde se infere que a identidade de gênero masculino ou feminino é uma construção cultural, determinada por padrões de uma sociedade. (WENCZENOVICZ e RANGEL, 2016, p. 148)

Nesse estudo, faz-se um recorte histórico crítico sobre o gênero, com objetivo a descortinar a cultura patriarcal, a repetição dos papéis masculino e feminino na sociedade, ampliando o debate na lógica de repensar a dimensão dos sujeitos a partir de conceitos diversos, reconhecendo os axiomas da complexidade, do pluralismo e da subjetividade, e associando nessa conjuntura outras categorias mais apropriadas a modernidade: a cidadania, a democracia, a justiça, a solidariedade, a reciprocidade e as políticas públicas.

Até o século passado, as mulheres permaneciam em âmbito doméstico, privado e os homens no espaço público, pois eram responsáveis pelo sustento da família. Muito embora, no século XXI, as mulheres tenham ocupado algumas posições no espaço público, tendo voz e vez, bem como o reconhecimento do corpo político, os papéis sociais exigidos pela sociedade do homem e da mulher dão continuidade, porém, o tempo e o espaço dessa repetição ou reprodução de papéis não são mais o mesmo do século passado, por isso, sua relevância na análise, da repetição na lei e nos conceitos. ${ }^{5}$

Nesse contexto, é importante sinalizar que o homem e a mulher, cada qual com um entorno ou campo social, cultural e econômico próprio, vivem e convivem com o outro, pairando a dúvida, se isso se dá e se perpetua pela construção social dada a repetição de papéis ou pela diferença essencial biológica, que pressupõe cérebros diferentes, ou seja, o cérebro masculino é sistemático e o cérebro feminino é empático (BARON, 2004). Sendo assim, a filosofia da diferença de Deleuze, convida a refletir, questionar, e até desconstruir conceitos, inclusive do próprio gênero, para compreender e avançar a partir de novos arranjos que podem se dar nas políticas públicas, depois desse enfrentamento (dos conceitos) em especial conforme a lei e seu destinatário, olhando para a generalidade, e especificidade.

Ao abordar a complexa temática da ressignificação de gênero e das relações delas circundantes a partir de uma abordagem sócio-histórica e política no Brasil observa-se a

5 Para descontruir conceitos, observando elementos de estrutura, recomenda-se dialogar com autores como Deleuze (2006), Foucault (2009), Bourdieu, (2005), Beauvoir (1970), Butler (2003). 
incidência da cultura patriarcal, a repetição dos papéis masculino e feminino na sociedade, ampliando e polemizando o debate na lógica de repensar a dimensão dos sujeitos a partir de conceitos diversos, reconhecendo os axiomas da complexidade, do pluralismo e da subjetividade, e associando nessa conjuntura outras categorias mais apropriadas a modernidade: a cidadania

Os movimentos do campo sempre tiveram a presença feminina, porém, inicialmente as pautas de luta centravam-se nas demandas universais como: acesso a terra, reforma agrária e políticas públicas, dentre outras contemplando a também as pautas da agricultura familiar. Nesse contexto, as mulheres vagarosamente foram buscando seus espaços e indicando também suas demandas e especificidades. Nesse aspecto Kaplan colabora:

\footnotetext{
Os mesmos estereótipos que ligam mulheres à natureza e impedem o avanço de mulheres como indivíduos e como cidadãs às vezes impulsionam mulheres a agir como mães com direitos adicionais. Paradoxalmente, ao aceitar e explorar as contradições de identidades coletivas como mães, como ativistas de base, frequentemente, ganham legitimidade como mulheres e como cidadãs. Explorando o fato de como a maternidade se relaciona ao bem-comum, levantam perguntas sobre conceitos, por exemplo, de como 'os direitos humanos' têm se desenvolvido fora da comunidade legal.(KAPLAN, 2001, p. 29).
}

Neste sentido resgatamos os Movimentos de Mulheres Trabalhadoras Rurais, que luta por direitos das trabalhadoras do campo, e que no nosso país se fortificou no período conhecido com abertura democrática, na década de 1980, ou seja, momento de transição da ditadura militar para o regime democrático, época também de efervescência de diversos movimentos de lutas sociais.

No Rio Grande do Sul, na Região Alto Uruguai, foi uma das regiões berço do Movimento de Mulheres Trabalhadoras Rurais (MMTR), como luta por direitos específicos e também como busca de inserção na sociedade, conforme Piran (2001, p.88-89):

O início da organização se dá com a luta pela aposentadoria aos 55 anos, mas logo se amplia para o direito a fazer o "bloco" para a venda de produtos em seu nome, reconhecimento da profissão de agricultora, direito de se associar às cooperativas.

Os seus objetivos e reivindicações eram os seguintes:

Objetivos:

-Acabar com a discriminação de que eram vítimas;

-Fazer a mulher participar dos diversos setores da sociedade;

-Valorizar o trabalho doméstico;

-Fazer com que a responsabilidade na educação dos filhos recaia sobre o casal, não apenas sobre a mulher;

-Conscientizar a mulher de seu valor e da importância da política;

-Despertar a mulher para sua libertação;

-Apoiar as lutas gerais dos trabalhadores;

Reivindicações:

-Aposentadoria aos 55 anos de idade para a trabalhadora rural;

-Lugares para lazer;

-Postos de Saúde; 
-Fim da violência contra a mulher;

-Auxílio-maternidade;

-Preço justo pelas mercadorias produzidas.

Podemos perceber que neste período as mulheres participavam com lutas específicas, mas que ao mesmo tempo faziam parte de um conjunto de reivindicações de todos os agricultores, porém antes mesmo deste momento de explosão dos movimentos sociais no Brasil na década de 1980, estão sendo questionados no mundo os sistemas econômicos, sociais e dos demais modos de vida como esclarece Siliprandi:

As conexões entre os movimentos de mulheres e os movimentos ecológicos estão em pauta no ocidente pelo menos desde a década de 1960, período em que eclodiram os movimentos da contracultura na Europa e nos Estados Unidos, questionando não apenas os grandes modelos políticos e econômicos - capitalismo e socialismo- mas o conjunto de instituições sociais, as ideologias, os valores que regulam os comportamentos dos indivíduos. Assim como se denunciam as relações opressivas entre os países - o imperialismo, a política armamentista, as guerras - politizavamse as relações pessoais, colocando-se em evidência os mecanismos de poder que estavam por trás do racismo, do sexismo e da postura irresponsável da humanidade para como o meio ambiente, por exemplo. Questionava-se um modelo civilizatório. (SILIPRANDI, 2009, p.68)

Neste sentido, a busca por alternativas de trabalho e renda de forma a contribuir também com uma sociedade com menores desigualdades e qualidade de vida surge o cultivo agroecológico. Esse desponta como um sistema de produção que busca o equilíbrio entre o homem e natureza, visando a sustentabilidade, com preocupação com a saúde, com o meio ambiente e com os contextos sócio-culturais.

A luta das mulheres fez com que elas se inserissem na sociedade e passassem a ver o seu próprio mundo com outros olhos, razão pela qual seu envolvimento pioneiro estar ligada a produção agroecológica. Essa ocorre, inicialmente, pela sua proximidade da residência através do cultivo de hortaliças, já que a horta sempre foi de sua responsabilidade e, em alguns casos dos filhos menores. Neste sentido também é importante ressaltar a divisão social do trabalho na constituição da propriedade:

O universo rural, alicerçado no casal, no modelo de família patriarcal é muito hierarquizado. Sendo assim observamos uma rígida divisão de papéis, tarefas e espaços. Ao homem são atribuídas as tarefas do trabalho da terra e as transações do mercado. Já à mulher cabe à responsabilidade de cuidar da casa, da criação de animais e o entorno como o quintal e a horta (PERROT, 2015, p.111).

Desta forma, a partir da produção agroecológica temos uma nova divisão social do trabalho e da renda dentro das propriedades familiares, oportunizando também a mulher um 
novo espaço de atuação. Porém, nem todos os espaços resultaram em 'libertação' integral dos ordenamentos patriarcais da propriedade familiar. Consoante a obtenção de uma pequena renda - agora de forma autônoma - a mulher permanece trabalhando nas demais atividades sem a devida divisão dos lucros. Mesmo que os dividendos sejam ínfimos em alguns casos há por parte do 'pai-patrão' a omissão de valores reais obtidos ao final das colheitas e vendas de produtos agrícolas.

Insta destacar que a Constituição Federal de 1988 em seu Artigo 5º, Inciso XXVI, ressalta que:

A pequena propriedade rural, assim definida em lei, desde que trabalhada pela família, não será objeto de penhora para pagamento de débitos decorrentes de sua atividade produtiva, dispondo a lei sobre os meios de financiar o seu desenvolvimento.

No contexto do Direito Agrário, O Estatuto da Terra (lei 4.504/64) tenta definir "propriedade familiar" e usa como referência de área, o módulo rural.

Art. $4^{\circ}$ Para os efeitos desta Lei, definem-se:

II - "Propriedade Familiar", o imóvel rural que, direta e pessoalmente explorado pelo agricultor e sua família, lhes absorva toda a força de trabalho, garantindo-lhes a subsistência e o progresso social e econômico, com área máxima fixada para cada região e tipo de exploração, e eventualmente trabalho com a ajuda de terceiros;

III - "Módulo Rural", a área fixada nos termos do inciso anterior;

Como é possível observar, o Estatuto da Terra dimensiona o que representa a propriedade rural explorada pela família e ainda, no Inciso III, determina que o módulo rural fixará a área da propriedade de família.

\section{A região Alto Uruguai}

A Região Norte do Rio Grande do Sul foi colonizada no início do século XX a partir do projeto do governo do Estado para povoar essa região de fronteira ainda desabitada pelo povo branco, porém com várias populações nativas e caboclas. No tocante a colonização, Ernesto Cassol, pesquisador local indica:

Carlos Barbosa, Presidente do RS, cria a Colônia Erechim. Com sede em Capoerê, em 6 de outubro de 1908. O ato se insere na política de imigração e colonização que, no período, o Governo do Estado implementava. Trata-se, pois, de colonização oficial, planejada, segundo a legislação vigente, sobretudo de 19899/1900, executada pelo organismo competente, a Inspetoria de Terras. (CASSOL,1979,p.28). 
Durante a década de 1910, com a construção da estrada de ferro São Paulo-Rio Grande que cortava a colônia e a conclusão da ponte sobre o Rio Pelotas e a abertura de nove estações "Erechim, Erebango, Capoerê, Boa Vista, Baliza, Barro, Viadutos, Canavial e Marcelino Ramos” (CASSOL, p.115) propiciou o desenvolvimento econômico da região e consequentemente a urbanização do decorrer das décadas seguintes.

Não podemos deixar de mencionar que mesmo antes da chegada dos imigrantes europeus, oriundos de outras regiões do Estado, estas terras eram habitadas por indígenas, caboclos, foragidos das revoluções. ${ }^{6}$ A colonização desta região se deu por imigrantes principalmente por alemães, italianos, poloneses, russos e israelitas, de acordo com a historiografia oficial. Porém, estudos recentes apontam que trinta etnias compuseram o mosaico que constituiu a Colônia Erechim, colocando em xeque as concepções cristalizadas de alguns memorialistas locais.

Em pesquisa a produção historiográfica da região, pode-se encontrar algumas informações interessantes acerca da formação do núcleo colonial e do seu desenvolvimento em um curto espaço de tempo, atentando que, este trecho foi extraído de uma obra contemporânea ao desenvolvimento local (1925):

\begin{abstract}
O principal núcleo colonial da região serrana é incontestavelmente este, criado em 6 de Outubro de 1908, pelo Estado, e instalado em 1910 com os primeiros 36 colonos, sendo 4 famílias com 28 pessoas e 8 solteiros. O seu desenvolvimento não tem ponto de comparação dentro ou fora de nosso Estado, posto que apenas em 8 anos a sua população aumentou de 32.000 habitantes e a produção, que era nenhuma, se elevou no mesmo espaço de tempo a 3.600:000\$000, dos quais foram exportados 2.574:000\$000. Dez anos apenas depois de fundada, e com oito anos somente de colonização efetiva, foi elevada à categoria de vila em 30 de Abril de 1918. A área total, medida e demarcada, desta colônia era de 105.624 hectares, restando por medir 305.640 hectares em 1912. A sua população em 1921 era de 40.650 habitantes dos quais cerca de 9.000 teuto-brasileiros. A sua receita nesse ano já atingia 128:100\$000 (PELLANDA, 1925, p. 189).
\end{abstract}

A região, até a década de 1980, teve como carro forte da economia a produção primária de cereais, como milho, trigo e soja, e a criação de animais. Entretanto, a partir desta década com o aumento a industrialização, aliada falta de políticas públicas para o campo, incidiu sobre a região um elevado número de agricultores e agricultoras trocando o campo

$6[\ldots]$ as matas de Erechim, que desde tempos imemoriais eram habitadas por numerosas tribos de índios, foram invadidas, durante os séculos XVIII e XIX por um grande número de aventureiros, bandeirantes, foragidos da polícia ou fugitivos das revoluções de 1835 e 1893, que ali estabeleceram suas toscas moradas, cobertas de taboinhas ou folhas de palmeiras (DUCATTI NETO, 1981, p. 74). 
pela cidade. Esse contingente se deslocou principalmente para a cidade de Erechim, que segundo Zanella (2003) nas últimas duas décadas do século XX teve o número de habitantes da zona urbana ultrapassando a rural.

A agricultura é marca característica desta região desde sua colonização, e a este respeito Wanderley (2013) aponta que as discussões sobre a definição de agricultura familiar tem duas vertentes, uma dos que se embaralham com a adotada operacionalmente dos beneficiários do Pronaf (Programa Nacional de Fortalecimento da Agricultura Familiar) e outra que considera agricultor familiar uma determinada faixa de agricultores que se adaptam as exigências de mercado em detrimento a outros produtores de pequeno porte que não são capazes desta adaptação as modificações. A segunda vertente é assim disposta:

\begin{abstract}
A ideia central é a de que o agricultor familiar é um ator social da agricultura moderna e, de uma certa forma, ele resulta da própria atuação do Estado. Na Europa, esta posição é reforçada pelo fato de que não só as políticas agrícolas nacionais, como a própria PAC, definiram como modelo de estabelecimento agrícola o estabelecimento familiar composto por duas unidades de trabalho, em geral, o casal familiar. (WANDERLEY, 2013, p.44)
\end{abstract}

Segundo Piran (2001), a agricultura se desenvolveu nesta região em dois momentos distintos, a tradicional e a moderna. A tradicional iniciou com a chegada dos europeus e foi até o final da Segunda Guerra Mundial e teve como característica a utilização intensa dos recursos naturais e a mão-de-obra familiar, já a segunda vai até os dias atuais e sua principal traço é a mudança do modo de produção e forçou a migração de agricultores para o Oeste Catarinense, Sudoeste do Paraná e para a maior cidade da região, Erechim.

Kozenieski (2016) aponta que o Censo agropecuário de 2006 foi um importante fator de contribuição para a caracterização da população do campo. Esse levantamento aponta que foram registradas 58.225 pessoas com vínculo em estabelecimentos agropecuários, sendo que destas, 51.016 possuem laços de parentesco com o produtor.

Em relação às características populacionais, ressalta-se ainda que $94,47 \%$ dos estabelecimentos rurais são dirigidos por homens. Além disso, destes que dirigem os estabelecimentos agropecuários, apenas $10,32 \%$ possuem idade inferior a 35 anos. A maior parte está na faixa etária de 35 a menos de 45 anos (23,48\%) e de 45 a menos de 55 anos $(28,51 \%)$. Os demais $37,79 \%$ dos dirigentes estão em faixas etárias superiores a 55 anos. Tais dados indicam um perfil majoritário de adultos e idosos no comando das atividades agropecuárias da microrregião. (KOZENIESKI, 2016, p.84)

Isso reforça a ideia que os homens ainda detêm o controle da esmagadora maioria das propriedades, fazendo que com cada vez mais o número de jovens, principalmente mulheres, 
continue migrando para os centros urbanos. Migram na ideia de obterem acesso a graus mais elevados de escolaridade e remuneração mensal. Aparentemente, a mulher rural migra em busca de melhor qualidade de vida, ou seja, trabalho, educação, saúde e lazer. As condições adversas dos centros urbanos se configuram em espaços de esperança em meio ao processo de favelização e desemprego. ${ }^{7}$

Para Mészáros (2002), o emprego e desemprego são uma simbiose (benéficos recíprocos) na medida em que o desemprego já está instituído quando se institui o emprego, as leis trabalhistas já na década de 1930 impõem restrições a força de trabalho estrangeira, e que atualmente se constituem na substituição da força de trabalho por máquinas. Aparentemente as tecnologias desempregam, no entanto, o desemprego não é resultado das tecnologias, mas da relação social que estabelece com o capital. O desemprego é necessário para o capital, e permite flexibilizar as relações de trabalho em virtude do imenso exército de reserva disponível, onde o desemprego é a regra.

\section{Análise de dados das entrevistas}

A fim de atingir os objetivos de análise, propostos na pesquisa, foram entrevistadas dez mulheres residentes, e com laboralidade nos municípios de Erechim (2), Itatiba do Sul (3), Severiano de Almeida (1) e Três Arroios (4). Da análise e interpretação de dados foi possível mapear a faixa etária, estado civil, número de filhos.

Os municípios em que estão inseridas as depoentes destoam entre si, enquanto Itatiba do Sul, Severiano de Almeida e Três Arroios tem como principais produtos econômicos a produção agrícola, Erechim é a cidade polo da região com forte industrialização e comércio.

Quanto a faixa etária da amostragem observou-se que a maioria concentra-se na faixa de 50 a 59 anos de idade, conforme o gráfico 1: 


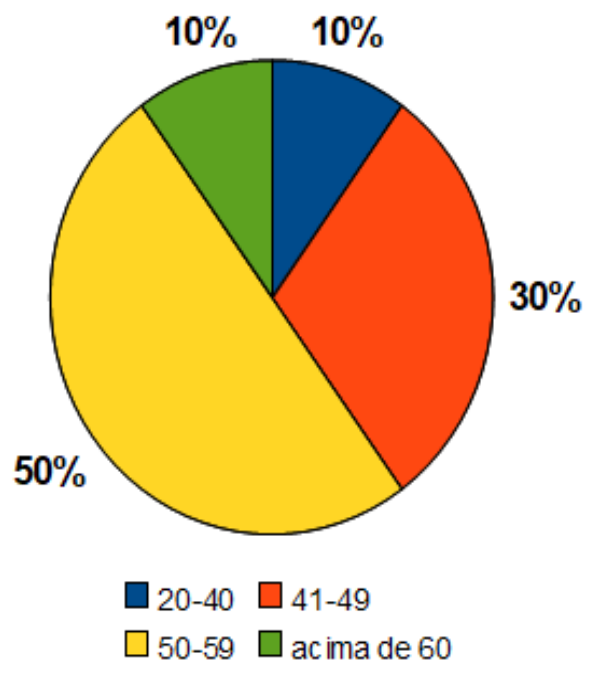

Gráfico 1 - Faixa Etária - Dados da Pesquisa

Ao analisar a faixa etária das mulheres é possível perceber a baixa incidência de jovens entre 20-40 anos, este dado aponta uma preocupante na região, que é a sucessão da propriedade de agricultura familiar.

O último Censo Agropecuário realizado pelo IBGE em 2006 registrou no Brasil a existência de 5.175.489 propriedades rurais, sendo 84,4\% destas, ou seja 4.367.902, reconhecidas como familiares com área média de 19 hectares. No Rio Grande do Sul são apontadas 441.467 propriedades, tendo 378.546 como familiares, destas a população maior de 14 anos é de 770.915 homens e 460.910 mulheres.

Os dados do Censo do IBGE (2010) indicam também números da população campesina na Região de estudo, Corede Norte do Rio Grande dos Sul, sendo esta é 62.896 pessoas em contraponto com 158.522 habitantes residentes em áreas urbanizadas.

A problemática da sucessão na agricultura familiar está ligada a permanência dos jovens no campo, que apesar de nos últimos anos terem políticas públicas voltadas para este público, bem como ações dos sindicatos ligados, a agricultura familiar, ainda esbara em questões complexas e interligadas:

A perspectiva de continuidade da agricultura familiar e d,e suas unidades produtivas depende de uma série de fatores que dificulta,m ou facilitam a permanência dos jovens. Esses fatores não são únicos e nem isolados, mas interligados entre si, e dizem respeito às condições sócio-econômicas familiares e da unidade produtiva; ao 
tipo de trabalho (agrícola ou não agrícola) realizado; às oportunidades de trabalho existentes na agricultura familiar e em atividades não agrícolas no meio rural ou nas cidades próximas aos locais de residência, para jovens de ambos os sexos; à educação; ao acesso ao lazer, ao tipo de lazer existente e às expectativas dos jovens sobre o lazer no meio rural; à participação e ao envolvimento em movimentos sociais; à possibilidade do jovem ter seu trabalho remunerado e autonomia para tomar decisões sobre seu trabalho e seus gastos pessoais; à perspectiva de herdar a propriedade; à percepção sobre o trabalho agrícola e o modo de vida no meio rural; ao acesso ao crédito e a políticas públicas de auxilio aos jovens; à perspectiva matrimonial com moças ou rapazes do meio rural. São dimensões que constroem as razões e as motivações dos jovens de querer ou não ser agricultor (a), de querer ou não ficar no meio rural. (BRUMER \& SPANEVELLO, 2008, p. 13)

Enquanto categoria - êxodo rural, temos exemplos de famílias que trocaram a cidade pelo campo e outras que adquiriram recentemente uma pequena propriedade e a mantem produzindo na condição policultora.

\begin{abstract}
$\mathrm{Na}$ propriedade, não faz muitos anos que a gente adquiriu a propriedade no interior, na Linha Lageado Antas - Três Arroios e lá então quando compramos tinham 500 pés de laranja, aí estas laranjas a gente procura ter elas orgânicas, sem aplicação de venenos e agrotóxicos, enfim e pensando no bem estar e na saúde que vemos que hoje em dia que as pessoas estão utilizando muito agrotóxico, então visando fazer algo diferente. (SCHIMITZ, 2017, p.1)
\end{abstract}

As depoentes revelaram também que a condição civil exerce uma linha tênue entre liberdade e manutenção de tradição, já que todas possuem o mesmo estado civil: casadas. Por muito tempo, e em muitos casos ainda, o matrimônio é o espaço de perdurar o patriarcado e apesar, destas não terem apontado sofrido violência, sabe-se que essa é uma das maiores causas de mortes de mulheres no Brasil, e em sua maioria através das mãos de seus maridos. Outro fator importante a se destacar, é que a dependência financeira também as inibe de procurar seus direitos, ou melhor denunciar quando são vítimas de violência doméstica.

No que tange as atividades desempenhadas no cotidiano em todas as entrevistas as depoentes apresentam em comum uma tarefa: os afazeres domésticos que incluem a limpeza da casa, elaboração das refeições, cuidado com a horta e pomar, dentre outras. "Cuido da casa, da cozinha, cuido da família, da roupa, da horta, da roça, das bergamoteiras, tiro leite, faço queijo, de tudo um pouco, faço açúcar mascavo" (BARROS, 2017, p.1)

Podemos perceber que mesmo com a chegada de novos ordenamentos sociais na área rural, a manutenção de algumas atividades se consolidaram e são quase impossíveis de se pensar em outra forma de execução, demonstrando a presença da hierarquia tradicional, onde as relações são construídas culturalmente e naturalizaram-se. Neste sentindo a francesa Elisabeth Badinter (1985) em seus estudos aponta que o amor materno é um mito, uma construção cultural e social e em contraponto com a crença que ser mãe é instinto e 
determinação da natureza. Esse conceito serviu para consolidar a imagem a mulher como mãe e um artificio para controlar a autonomia feminina. A mesma autora afirma que a mulher não precisa da maternidade para ser feliz.

Além de casadas, outro aspecto em comum a toda amostragem é a presença de filhos, demostrado no gráfico 2.

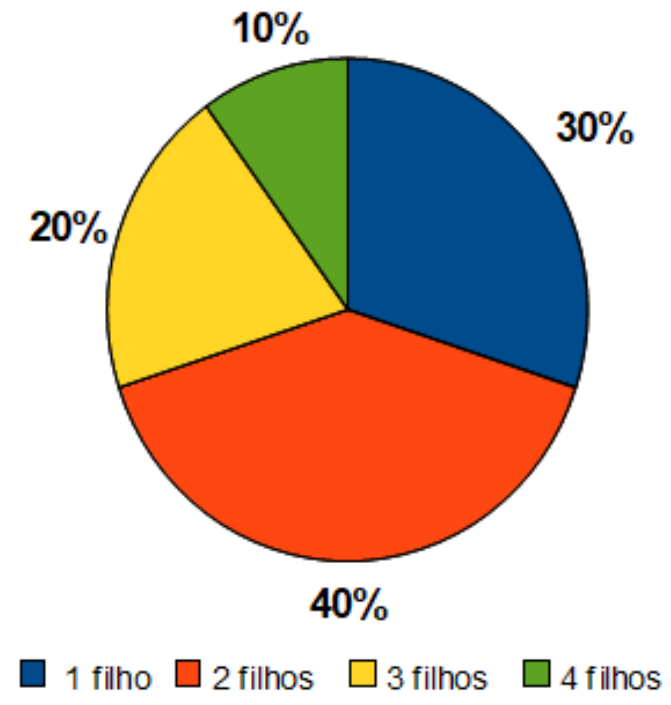

Gráfico 2 - Número de filhos/as - Dados da pesquisa

Seguindo a mesma problemática da sucessão da propriedade, apesar de constatar que todas possuem filhos, em parte delas relatam que os filhos não estão mais trabalhando na propriedade.

A divisão sexual do trabalho é um constante questionamento dos movimentos feministas e no ambiente rural esta segmentação é ainda mais enraizada. Entretanto, conforme aponta Ostrovski (2017) não tem na sua casa serviços específicos dos homens e das mulheres "Aqui a função da nossa família ela é mais ou menos assim igual para todos, bom eu tô aqui eu faço as atividades de casa, eu vou para a roça" (Ostrovski, 2017, p.2).

Já no quesito escolaridade, observa-se que duas depoentes mulheres possuem ensino superior completo. As outras apresentam em maior incidência o ensino médio completo 
(30\%) e em seguida o ensino fundamental incompleto (30\%).

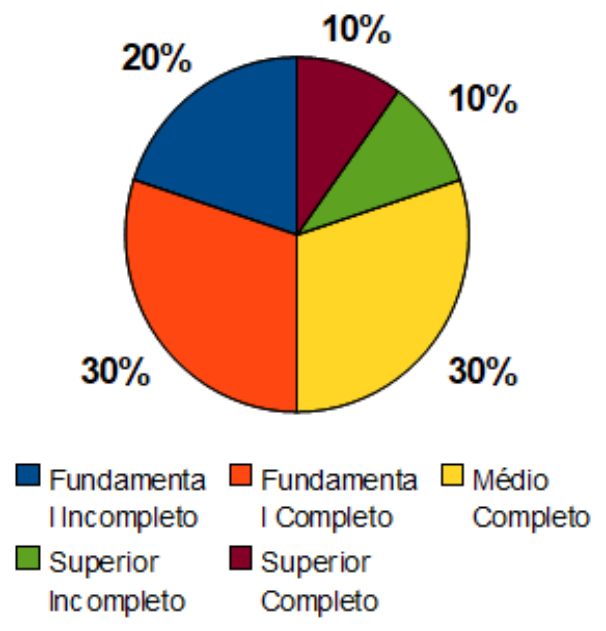

Gráfico 3 - Escolaridade - elaborado pela autora

Em outro item da pesquisa, é possível sinalizar a relação da opção pelo uso da produção orgânica. Através dos depoimentos constata-se que a substituição do modelo convencional de produção de alimentos para o orgânico foi o resultado de um processo de conscientização de um ou mais membros do grupo familiar. Dentre os principais estímulos a mudança está a chegada de doenças por uso de agrotóxicos, falência financeira e demais. Segundo a depoente Idete: "Os orgânicos chegou assim, nós estávamos sempre doentes, a gente vivia no hospital, e dai surgiu uma oportunidade para gente começar com os orgânicos e tentou e estamos super felizes hoje".

Carneiro (2015) na obra "Dossiê da Abrasco" divulga um relatório com dados da alta incidência de resíduos de agrotóxicos presentes diariamente na mesa dos brasileiros "Um terço dos alimentos consumidos cotidianamente pelos brasileiros está contaminado pelos agrotóxicos, segundo análise de amostras coletadas em todas os 26 estados do Brasil, realizada pelo Programa de Análise de Resíduos de Agrotóxicos em Alimentos (PARA) da Anvisa (2011)”. (CARNEIRO, 2015, p. 56)

Gasparin (2017) reforça a preocupação com a saúde da família e do consumidor:

[..]eu penso na nossa na nossa saúde a gente usa tudo produtos mais naturais, que até outro dia, a própria galinha a gente se cria, o próprio porco a gente se cria, as hortas a gente sabe o que colhe que é coisa que não se passa nada, a mandioca, tudo a gente come, as frutas não tem nada até pra nossa saúde é muito importante pra saúde de toda nossa família e pra quem nós vendemos porque o que nós comemos, é vendido pros outros também. (GASPARIN, 2017, p.3)

Além das atividades da propriedade as mulheres exercem outras atividades 
profissionais. Gasparin também atua entre a produção de hortaliças e como funcionária pública do município de Três Arroios, onde a dezenove exerce o cargo de agente comunitária de saúde. Já Orilde começou a se dedicar a agricultura após a aposentadoria como professora:

De 1975 até 2000 eu fui professora de primeira a quarta série, depois que eu me aposentei, eu tinha 42 anos na época, eu comecei a me dedicar agricultura. Com orgânicos, deixa eu ver quanto tempo faz com orgânico, no começo ali era convencional acho que é uns 10 anos, de 2009 pra cá foi que a gente começou a trabalhar nos orgânicos (POLONI, 2017, p.1).

Outro apontamento se refere a liberdade que esse modelo de produção oferece a estas mulheres, de não estar ligada por contratos de produção com grandes indústrias nacionais e estrangeiras que fazem com que os agricultores tenham contratos de entrega em determinado tempo de aves e suínos.

Eu acho que assim, a gente sempre deu valor para os produtos orgânicos porque tu tá plantando, colhendo e vendendo saúde em primeiro lugar e também questão de renda de tu produzir, vender em feiras, em ser produtos orgânicos, teu custo bem menor, tu faz todo o ciclo, completo, porque tu tem o teu adubo, faz compostagem, tem a tua semente, porque primeiro tu cuida da tua semente para ter para o ano que que vem, daí tu colhe teus produtos que é para a subsistência da família e o que tu sobra vai vender para ter a renda e daí com isso tu vai motivando e também uma coisa que motiva muito é porque a gente trabalha em grupo, então a gente não vive aquela solidão dentro de um "chiqueirão", tu não tá isolado, tu sabe que tem um grupo de pessoas que pensam que nem você, que compartilham das mesmas dificuldades, das mesmas alegrias, das mesmas conquistas, tudo isso te ajuda a te motivar, tu tem os mesmos assuntos e assim vai. (OSTROVSKI, 2017, p.3)

Ao questioná-las como o orgânico chegou a sua propriedade apontamento de que foi via o CETAP - Centro de Tecnologias Alternativas Populares, que apresentou esta modalidade de produzir, bem como treinamentos e apoio para organizar desde a produção até a comercialização.

A experiência tem mostrado, no entanto, que a participação em processos de transição para a agroecologia, ao introduzir elementos que potencialmente desestabilizam a lógica patriarcal, pode abrir espaço para a mudança dos padrões de gênero, criando brechas para o reconhecimento de alternativas de vida às mulheres, para além dos papéis tradicionais. Mas para quebrar essa lógica é preciso que haja um processo de "empoderamento" também político dessas mulheres: o que vai depender basicamente que elas consigam aparecer (individual e coletivamente) como sujeitos ativos, nas famílias, nas comunidades, até influenciarem nas instituições públicas, nas políticas, na sociedade. Enfim, que elas sejam reconhecidas. (SILIPRANDI, 2010, p. 126)

No quesito religiosidade apurou-se os seguinte dados: 


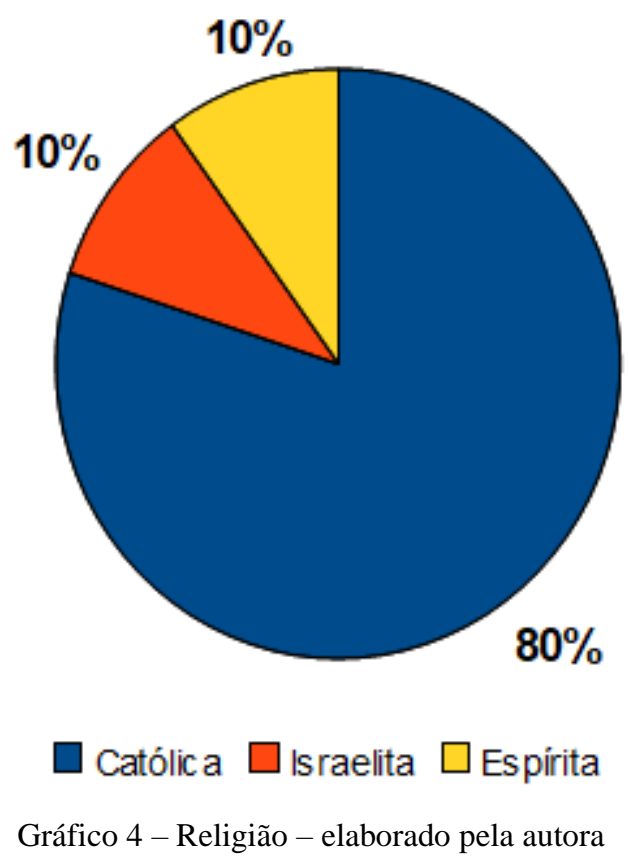

A religiosidade na região vem acompanhada pelo discurso da unicidade de credo: catolicismo católico. Esse item sócio-cultural também traz consigo os desdobramentos das atividades de lazer/festivas: tríduo, festas de padroeiros, romarias, dentre outras. Postura essa que reforça o ideário de monogamia, patriarcado e submissão da mulher no contexto social.

\section{CONCLUSÃO}

Reconhecidamente a atuação das mulheres na agricultura familiar e sua inserção no processo de produção agroecológica na região do Alto Uruguai/RS foi reflexo dos desdobramentos a respeito da condição feminina nos campos público e privado, como foi destacado no decorrer desse estudo. Recentemente, ou melhor, desde meados de 90 se tem estudado sobre os homens e as masculinidades com o fito de trazer novos aportes e avançar na discussão em que eles também precisam ser considerados protagonistas juntamente com as mulheres nas conquistas junto a agricultura familiar. Contudo, não dá para desconsiderar o campo social as desigualdades de poder em que o homem e a mulher estão envoltos, por isso toda a necessidade de discussão e ampliação de espaço para a atuação das mulheres nesse campo de atuação.

Podemos perceber que a agroecologia contribuiu para a visibilidade do trabalho feminino dentro das propriedades, mesmo que antes da implantação deste modo de produção 
também realizassem tarefas produtivas, mas por meio da participação em feiras, organização da comercialização ficou mais visível este trabalho antes visto com improdutivo economicamente, bem como desempenham um papel estratégico dentro deste sistema.

\section{REFERENCIAS BIBLIOGRÁFICAS}

BADINTER, Elisabeth. Um amor conquistado: O mito do amor materno. Rio de Janeiro: Nova Fronteira: 1985.

BARON, Simon Cohen. Diferença essencial: A verdade sobre o cérebro de homens e mulheres. Rio de Janeiro: Objetiva, 2004.

BEAUVOIR, Simone. O segundo sexo: fatos e mitos. 4. ed. São Paulo: Difusão Europeia do Livro, 1970.

BOURDIEU, Pierre. O poder simbólico. 8. ed. Rio de Janeiro: Bertrand Brasil, 2005.

BUTLER, Judith P. Problemas de gênero: feminismo e subversão da identidade. Rio de Janeiro: Civilização Brasileira, 2003.

BRUMER, A.; SPANEVELLO, R. M. Jovens agricultores da Região Sul do Brasil. Porto Alegre: UFRGS; Chapecó: Fetraf-Sul/CUT, 2008. Relatório de Pesquisa.

CASSOL, Ernesto. Histórico de Erechim. Passo Fundo: Instituto Social Padre Berthier, 1979.

DELEUZE, Gilles. Diferença e repetição. 2. ed. Rio de Janeiro: Graal, 2006.

DUCATTI NETO, A. O Grande Erechim e sua história. Porto Alegre, Grafosul, 1981.

FREIRE, Paulo. Pedagogia da Esperança: um reencontro com a pedagogia do oprimido. Rio de Janeiro: Paz e Terra, 1992.

KAPLAN, T. Uncommon Women and the Common Good: Women and Environmental Protest. In: ROWBOTHAM, S.; LINKOGLE,S. (Ed.). Women Resist Globalization: Mobilizing for Livelihood and Rights. London: Zed Books, 2001, p. 28-45.

MÉSZÁROS, István. Para Além do Capital. São Paulo: Boitempo Editorial; Campinas: Editora da UNICAMP, 2002.

PELLANDA, E. 1925. Colonização germânica no Rio Grande do Sul. Porto Alegre, Livraria do Globo, 372 p.

PERROT, Michelle. Minha história das mulheres. São Paulo: Ed Contexto, 2015.

PIRAN, Nédio. Agricultura familiar: lutas e perspectivas no Alto Uruguai. Erechim: EdiFAPES, 2001.

SAQUET, Adriano Arriel. Reflexões sobre a agroecologia no Brasil. IN: ALVES, Adilson F.; 
CORRIJO,Beatriz R.; CANDIOTTO, Luciano Z. P. Desenvolvimento territorial e agroecologia. São Paulo: Expressão Popular, 2008.

TEDESCO, João Carlos. Agrodiversidade, agroecologia e agricultura familiar: velhas e novas faces de um processo de desenvolvimento na região de Passo Fundo - pós anos 90. Passo Fundo: UPF, 2006.

DE ARAÚJO RANGEL, Carlos Eduardo; WENCZENOVICZ, Thaís Janaina. Gênero $e$ violência: interfaces com as políticas públicas no estado do Rio Grande do Sul e Rio de Janeiro. Barbarói, n. 47, p. 144, 2016.

ZANELLA, Anacleto. A trajetória do sindicalismo no Alto Uruguai gaúcho (1937-2003). Passo Fundo: Universidade de Passo Fundo,2004.

\section{FONTES ELETRÔNICAS}

BRASIL. Constituição da Republica Federativa do Brasil, 05 de outubro de 1988. Disponível em: www.planalto.gov.br/ccivil_03/constituicao/constituicaocompilado.htm. Acesso em: 16 setembro de 2017.

BRASIL. Lei n.4.504 de 30 de novembro de 1964. Dispõe sobre o Estatuto da Terra e dá outras providências. Disponível em: http://www.planalto.gov.br/ccivil_03/leis/14504.htm. Acesso em: 16 setembro de 2017.

CARNEIRO, Fernando Ferreira (Org.). Dossiê ABRASCO: um alerta sobre os impactos dos agrotóxicos na saúde. Rio de Janeiro: EPSJV; São Paulo: Expressão Popular, 2015.

Disponível em: DossieAbrasco_2015_web.pdf. Acesso em 21 de agosto de 2017

IBGE - Censo Agropecuário, 2006. Disponível em http://www.ibge.gov.br. Acesso em 22 ago. 2017 .

KOZENIESKI, Éverton de Moraes. A produção do espaço rural: transformações das dinâmicas produtivas e da agricultura na microrregião de Erechim. 2016. Disponível em http://www.lume.ufrgs.br/bitstream/handle/10183/151330/001011366.pdf?sequence $=1$. Acesso em 24 ago. 2017.

SILIPRANDI, Emma. Mulheres e Agroecologia: a construção de novos sujeitos políticos na agricultura familiar. 2010. Disponível em http://repositorio.unb.br/handle/10482/5591. Acesso em 30 Mai. 2016.

WANDERLEY, Maria de Nazareth Baudel. Agricultura familiar e campesinato: rupturas e continuidade. Estudos sociedade e agricultura, v. 1, 2013. Disponível em

http://r1.ufrrj.br/esa/V2/ojs/index.php/esa/article/view/238. Aceso em 22 ago. 2017.

\section{FONTES}

BARROS, Anir Marta. Depoimento (julho de 2017). Entrevistadora: Daiana Paula Varotto. Erechim/RS: UERGS, 2017. Arquivo wav.

BERTOCHI, Ivanir Wilma Menegat. Depoimento (julho de 2017). Entrevistadora: Daiana 
Paula Varotto. Erechim/RS: UERGS, 2017. Arquivo wav.

GASPARIM, Ivete Inês. Depoimento (agosto de 2017). Entrevistadora: Daiana Paula Varotto. Erechim/RS: UERGS, 2017. Arquivo wav.

MADER, Marilice. Depoimento (julho de 2017). Entrevistadora: Daiana Paula Varotto. Erechim/RS: UERGS, 2017. Arquivo wav.

OSTROVSKI, Zelinda Polli. Depoimento (agosto de 2017). Entrevistadora: Daiana Paula Varotto. Erechim/RS: UERGS, 2017. Arquivo wav.

POLONI, Orilde Natalina Nadaletti. Depoimento (julho de 2017). Entrevistadora: Daiana Paula Varotto. Erechim/RS: UERGS, 2017. Arquivo wav.

RUDNISKI, Ivanilda Fatima. Depoimento (julho de 2017). Entrevistadora: Daiana Paula Varotto. Erechim/RS: UERGS, 2017. Arquivo wav.

SCHIMITZ, Daniela Prestes. Depoimento (abril de 2017). Entrevistadora: Daiana Paula Varotto. Erechim/RS: UERGS, 2017. Arquivo wav.

SENTCOVSKI, Idete Maria Vendrusculo. Depoimento (junho de 2017). Entrevistadora: Daiana Paula Varotto. Erechim/RS: UERGS, 2017. Arquivo wav.

TODESCATT, Fabiane Ferraso. Depoimento (junho de 2017). Entrevistadora: Daiana Paula Varotto. Erechim/RS: UERGS, 2017. Arquivo wav. 